\title{
The Use of Literature in the Language Classroom: Methods and Aims
}

\author{
Koutsompou Violetta-Irene
}

\begin{abstract}
Literature in a language classroom provides enough space for the learners to comment, justify and mirror themselves. By using literary text the language class can turn out to be lively and motivating. This article's main purpose is to provide you with the appropriate information through a literature review concerning the use of literary texts in language learning as well as its benefits. Furthermore, in this article, there are presented the different aspects of literature methods based on theories and organized activities according to a group of Greek intermediate students.
\end{abstract}

Index Terms-Activities, children, English, methods.

\section{INTRODUCTION}

Bearing in mind that in the last decade, there has been an upsurge of interest in how literary texts can be used with the language learner, this article's main purpose is to suggest ways of using literature in the classroom helping the students improve the English language. This can be achieved through specific activities based on a literary text ("Little Women" by Louisa May Alcott) and, of course, by adjusting the text with a particular group of students (intermediate Greek students). Basically, we will focus on the question of what is literature, the multiple values of teaching literature in the classroom, how literature helps the student develop the basic skills (speaking, writing, reading), and the reasons for choosing this particular text and finally, provide the exercises originating from this text.

\section{WHAT IS LITERATURE?}

There are many different definitions given to the above question. Here are some given by teachers from all over the world [1]:

1) Literature is the "feelings" and "thoughts" in black and white.

2) Literature is a world of fantasy, horror, feelings, visions ... put into words. Here are also other quotations which "define" literature.

Literature could be said to be a sort of disciplined technique for arousing certain emotions [2].

Great literature is simply language charged with meaning to the utmost possible degree [3].

According to Boas [4] "literature is the record of experience interpreted by personality that behind every book which the race has preserved is a human being's eager effort

Manuscript received November 10, 2013, revised January 22, 2014.

Koutsompou Violetta-Irene is with City Unity College, Athens, Greece (e-mail: v.koutsompou@cityu.gr, k_violetta120@yahoo.com). to give life meaning, to create beauty, to express vivid emotions and ideas, to make men aware of themselves and the life they lead". The above extract presents an integrated meaning of the value and the importance of literature.

\section{HISTORICAL REVIEW}

Literature and language are closely related and this is a fact none can deny. Literature is constituted by language and it represents one of the most recurrent uses of language. Language and linguistic analysis can also be employed to access literature from the learner's point of view. Brumfit and Carter [5] already emphasized the role of literature as "an ally of language". This technique is by no means novel, since literature has been a widely used teaching tool in different language teaching methods. However, here the perspective changes giving more relevance to the literary text as a work of art. First of all, let us go over the changing role of literature in the tradition of second language teaching to end with an account of its current situation within the communicative approach. In the grammar translation method, literature was the central component.

Literary texts of the target language were read and translated, used as examples of good writing and "illustrations of the grammatical rules" [6]. The focus of this teaching method was on form, on learning the rules of grammar and the lexical items as they appeared in the text. There was no literary interest, nor interest on content. After this method fell in disuse, literary texts also went forgotten for teachers of second languages. For the structural approaches to language teaching, literature was discredited as a tool, because it represented the old tradition. The functional-notional method ignored literature, because in this method the importance lies on communication and they present authentic language samples. Literature was not considered either to have a communicative function or to be authentic example of language use. Nonetheless, in the last decade or so the interest in literature as one of the most valuable language teaching resources available has revived remarkably [7]. This is in consonance with the new currents within the communicative approach that see in reading literature the perfect realization of their principles namely developing communicative competence, that is teaching learners to communicate in the second language and accounting for real, authentic communicative situations [8].

Literature reading is, no doubt, a communicative activity and literary texts are who could nowadays deny such thing, authentic examples of language use. Many authors, among them Brumfit and Carter [9] and Lazar [10], reject the idea of the existence of a specific literary language and claim that the 
language used in literary texts is common language with a high concentration of linguistic features like metaphors, similes, poetic lexis, unusual syntactic patterns, etc. These are not literature specific since these features also appear in ordinary language use and also in nursery rhymes, proverbs or publicity slogans, just to cite a few examples, however, in literature these show a higher incidence. We talk therefore, of a literary use of language.

\section{CRITERIA FOR USING LITERATURE}

There are three main criteria that justify the use of literature as a second language teaching tool [11]. Firstly, the linguistic criterion defends that literature should be used in language teaching, because it provides the learner with genuine, authentic samples of language, and also with real samples of a wide range of styles, text types and registers. It is extremely important for foreign language learners to be trained in a variety of registers, styles and genres and to be able to differentiate the purpose of each of them. These different manifestations of language are not only distinctive linguistically, but also socially, they all have a social communicative function. This has to do with the notion of adequacy. It refers to the fact that a message needs to be linguistically correct and situationally appropriate, as regards not only its content, but also its form for a more detailed account on the notion of adequacy and its relationship to communicative competence.

The second criterion is methodological and refers to the fact that a literary text has multiple interpretations, these generate different opinions among the learners and this leads to real, motivated interaction with the text, with the fellow students and with the teacher. Interaction is one of the bases of the communicative approach which defends that it is by interacting, by communicating, that the language is learned. From the methodological point of view, further aspects that favor the use of literature in the language classroom are the active role of the learner and the literary text as the central focus of attention. Learners become active, autonomous, and central to the learning process. One aspect of special importance within the communicative approach is the idea of literature supplying the learner with cultural information about the country whose language they are learning. Our response to the cultural aspect as reflected in literature should be critical. Lastly, the motivational criterion is of great relevance because the literary text shows the real feelings of the writer and this generates a powerful motivation in the learner. With the literary text the student accesses this personal experience, if she is touched by the theme and provoked, she will be able to relate what she is reading to her world, to what she knows and feels. Designing stimulating activities that motivate the learners is the greatest challenge for language teachers, and literature has a strong motivating power due to its calling on to personal experience.

\section{WHY USE LITERATURE?}

The purpose of using literature in a language classroom is to make the class interactive and it can be stated that an interactive class can obviously improve communicative competence of the learners and keep a lasting impact on their mind. Such a class can enhance the critical thinking abilities of the learners and at the same time maintain a learner centre environment. Literary texts are a rich source of classroom activities and can surely prove to be very motivating for learners. No wonder the use of literary pieces play a significant role in English Language Teaching. Literature opens a new world to the students. It cultivates the critical abilities of the students. It encompasses every human dilemma, conflict and yearning unraveling the plot of a short story is more than an automatic exercise.

It demands a personal response from the learners and encourages them draw on their own experiences. By doing so, learners become more personally invested in the process of language learning. The use of literature is to focus on the positive contributions of a literary text as it exposes the learner to different registers, types of language use. An attractive and enjoyable short story that conveys our feeling or emotion can touch the learners' heart instantly.

Consequently, the language class becomes not only exciting but also it reciprocates with impulsiveness and interest. This genuineness in learning leaves a lasting impact on the students' mind. The dialogic nature of literary pieces paves the way for individual learner's response to a particular piece of literature that ensures his or her use of creative faculty, of course through language. Such learning drives away the monotony of traditional language classes. Thus, it gives the teacher an opportunity to open a broad context of language use for the students.

Three main reasons for the teaching of literature have been consistently advanced. Each embraces a particular set of learning objectives for the student. These are:

1) The cultural model

2) The language model

3) The personal growth model

The models may be summarized as follows:

\section{A. The Cultural Model}

Teachers working within such an orientation stress the value of literature in encapsulating the accumulated wisdom, the best that has been thought and felt within a culture. Through literature students get to know the background not only of the particular novel but also they learn about history, society, and politics of the country described in the novel or story. By experiencing this, they open themselves to understanding and appreciating ideologies, mentalities, traditions, feeling, and artistic form within the heritage the literature of such cultures endows.

\section{B. The Language Model}

One of the main reasons for a teacher's orientation towards a language model for teaching literature is to give students knowledge with some sense of the more subtle and varied creative uses of language. A main impulse of language-centered literature teaching is to help students find ways into a text in a methodical way and for themselves. If we take into consideration that "literature is made from language" (Boas, we can easily conclude that if students can improve their reading abilities they will be able to come to terms with a literary text as literature. 


\section{The personal Growth Model}

Teachers are very interested in the personal growth model of the students. Teachers' main goal is to help students achieve an engagement with the reading of literary texts (Boas). Helping students to read literature more effectively is helping them to grow and mature as individuals as well as their relationships with the people around them. To encourage personal growth the teacher has to select texts to which students can respond and to which they can use their ideas and imagination creatively.

\section{SHORT STORIES}

There are several advantages for using short stories in an ESL classroom. The most revealing one is their practical length, which allows the student to conclude the task of reading on one sitting, or depending on the teachers' approach, it can be entirely read within one or two class lessons [12]. As students are always worried about the amount of work they need to perform and often have the feeling of being overwhelmed, reading short stories seems to be less frightening, for their own definition suggests, they are "short". And because they are short, short stories can be applied more frequently, which means that a greater number of short stories can be employed and that, consequently, increases the possibility of finding pieces that are appealing to each individual's tastes and interests. Still pertaining to its length, short stories can be applied to any course, no matter its level or duration. Another major characteristic of short stories is that they are extremely compressed. Even though it denotes a good attribute because the students access a great deal of information by reading fewer words, it also hides the problem of engaging economy of language and imagery, which can keep the reader from appreciating the quality of the work, even after understanding its theme. It is the teacher's duty to guide the students on this journey, for when reading a short story; the students "are invited to see the universe in a grain, of, sand, and when they look at the grain of sand, they must be helped to see the universe within it, and to respond to it on an emotional level".

Short fiction is a supreme resource for observing not only language but life itself. In short fiction, characters act out all the real and symbolic acts people carry out in daily lives, and do so in a variety of registers and tones [13]. The world of short fiction both mirrors and illuminates human lives [14]. The inclusion of short fiction in the ESL / EFL curriculum offers the following educational benefits [15]:

- Makes the students' reading task easier due to being simple and short when compared with the other literary genres, enlarges the advanced level readers' worldviews about different cultures and different groups of people,

- Provides more creative, encrypt, challenging texts that require personal exploration supported with prior knowledge for advanced level readers,

- Motivates learners to read due to being an authentic material,

- Offers a world of wonders and a world of mystery,

- Gives students the chance to use their creativity,

- Promotes critical thinking skills,

- Facilitates teaching a foreign culture (i.e. serves as a valuable instrument in attaining cultural knowledge of the selected community,

- Makes students feel themselves comfortable and free,

- Helps students coming from various backgrounds communicate with each other because of its universal language,

- Helps students to go beyond the surface meaning and dive into underlying meanings,

- Acts as a perfect vehicle to help students understand the positions of themselves as well as the others by transferring these gained knowledge to their own world.

In brief, the use of a short story seems to be a very helpful technique in today's foreign language classes. As it is short, it makes the students' reading task and the teacher's coverage easier. An important feature of short fiction is its being universal. To put it differently, students all over the world have experienced stories and can relate to them. Moreover, short fiction, like all other types of literature, makes contribution to the development of cognitive analytical abilities by bringing the whole self to bear on a compressed account of a situation in a single place and moment.

\section{ThE THREE BASIC SKILlS}

According to the above information we understand that literary texts can be very useful in order to motivate students to develop three basic language skills: a) reading b) writing and c) speaking. Before tackling a literary text we should, as EFL teachers, prepare activities that will help students advance their level in these three basic skills. Here, we will not going to expand the theme of the basic skills due to the fact that through the activities the author prepared and present in the following pages it will be obvious how literature helps students to develop their skills. (Further information can be found in Collie and Slater, p. 5, Widdowson, ELT Journal, vol. 3, p. 31 and Brumfit and Carter, p. 188-198).

\section{FACTORS TO CONSIDER WHEN SELECTING LITERARY TEXTS}

The text which was selected here to work with is Louisa May Alcott's "Little Women". It has been used a simplified version of it (Oxford, stage 4) because the author had in mind a group of Greek students in an intermediate level, who generally have the following characteristics:

Age of students: eleven to thirteen years old

Gender: mixed

Educational lives: late years in primary school up to first/second hear of high school

Social background: middle class

Literary background: sufficient

This text has been chosen since the writer believes that it can broaden students' minds meaning that they will become familiar with the culture and the values of the specific time period described in the book. They will find out historical events (war in the south) and they will face the women's position and the dress code of that time, the acceptable behavior and generally they will "meet" a different society and learn how people lived back then. The language is the 
appropriate one for their level and as a result, metalanguage is not required.

\section{TyPes OF ACTIVITIES USED}

There are many ways to follow when preparing activities for short stories. One of them is to classify them into three basic groups:

1) Pre-reading activities

2) While-reading activities

3) Post-reading activities

The above classification is recommended by Lazar (1993) but also from various other academics such as Tomlinson.

In my opinion, the headings help a lot when organizing ideas and thoughts related to the tasks and exercises which will be used with the literary text.

To this point, we should mention that the text is divided in two sections:

Section $\mathrm{A} \rightarrow$ from the beginning to chapter 7

Section B $\rightarrow$ from chapter 7 to the end

It has been decided to make this division for the reason that it seems that it would be easier for the students to read it this way, but also because the writer will have the opportunity to teach equally the specific text.

\section{A. Section A}

\section{1) Pre-reading activities}

This kind of activities helps students to understand the cultural background of the story. They stimulate the students' interest in the story, makes them become more focused on it and motivate them to want to learn what finally happened in the story.

Activities like these teach the learner new vocabulary and this is very important because he/she expands his speaking and writing ability using new words (Lazar).

1) Exercise 1

The title of the story is "Little Women". What do you think the story will be about?

2) Exercise 2

- Have you ever heard of this book? Do you know anything about the writer?

- Meg, Jo, Beth, Amy. These are the names of the 4 girls in the story. Judging from the names I want you to tell me what do you think their character will be?

- Do you know anything about the Civil War taking place in those days?

- What do you believe the women's position was back then?

- Do you know about the dress code in those days? Make a short list of types of clothes.

\section{2) Homework}

1) Exercise 3

Read the first 7 chapters of the story

\section{While-Reading Activities}

These activities help students (Lazar):

1) To understand the plot.

2) To understand the characters
3) With difficult vocabulary

4) With style and language

Having in mind the above criteria, the following exercises can be used for the first sections of the text.

\section{A. Understanding the Plot}

1) Ex. 1. Read the text and provide titles for each thematic unit.

2) Ex. 2. Form groups of two and write a small summary.

3) Ex. 3. Listen to the summaries of your classmates. Do you think you or they have missed something? Do you want to add something?

\section{B. Understanding the Characters}

1) Ex. 1. Which are the characters that appear in this section of the story? Make a list.

2) Ex. 2. Write answers to these questions. (Chapters 1-3).

- Why wasn't the girls' father at home that Christmas?

- Why did Mrs. Hummel almost cry with happiness?

- What happened to Meg's hair before the New Year's Eve party?

- How did Meg get home with her bad ankle?

3) Ex. 3. Can you think of words that would fit in describing any of the girls' characters?

\section{Helping with Difficult Vocabulary}

1) Ex. 1. While you are reading, underline the unknown words that you think prevent you from grasping the meaning.

2) Ex. 2. Match each word listed below, to one of the meanings. Check your answers with a partner.

- Pretend: 1) make it seem that sth is the case when in fact it's not

- b) gossip: 2) very bad or wrong

- c) wicked: 3) a private teacher for a child or children at their home

- d) tutor: 4) to talk about other people, often unkindly

D. Helping with Language

1) Ex. 1. Choose the best word to join the sentences together.

- We invited the Laurence boy to our party and/but he didn't come.

- Beth was very shy although/so she didn't go to school.

- Jo was very angry indeed while/when Amy burned her notebook.

- They enjoyed being lazy although/and the days seemed very long.

We would all be very sorry unless/if anything happened to you.

\section{Post-Reading Activities}

The post-reading activities help students (lazar):

- To make interpretations of the text

- To understand the narrative point of view

- Practice the language skills

- Helping learners to express their personal view points and experiences

\section{A. Interpreting the Text}


1) Ex. 1. "Beth was much too shy to go to school with other children, so she studied at home with her father". What do these lines; tell us about Beth's character?

\section{B. Practicing Language Skills}

1) Ex. 1. Write five statements about the first section of the story. Two statements should be true and the other three false.

2) When you have finished writing the statements show them to the person sitting next to you, and ask them to tell you which statement is false and why.

\section{Homework}

1) Ex. 2. Write your own version of what you think happens in Section B.

\section{Students' Personal Growth}

1) Ex. 1. In the novel there are reflected strong family relationships. Do you believe that nowadays families have such feelings? Generally, how have relationships changed? In what ways?

\section{E. Section B}

\section{1) Pre-reading activities}

1) Ex. 1. Compare your expectations elicited by the title with the part of the story you have read. Discuss the differences and similarities.

2) Ex. 2. Tell the rest of the class how you think the story evolves.

2) While-reading activities

3) Understanding the plot

1) Ex. 1. Read the text and provide titles for each thematic unit.

2) Ex. 2. Write a summary of the text and then link it to the summary you wrote for Section A, so as to present a coherent text.

\section{4) Understanding the character}

1) Ex. 1. Make a list of the characters that appear in Section b. Check your Section A list. Which of these characters do you like most and why?

5) Helping with vocabulary

1) Ex. 1. While you are reading underline the unknown words that you think prevent you from grasping the meaning.

2) Ex. 2. Find the words in the text which mean the following:

- to become an adult

- a plaything for a child

- an alcoholic drink made from grapes

A message sent very quickly by electricity on radio.

6) Post-reading activities

7) Interpreting the text

1) Ex. 1. Who said these words, and when? (Chapters 10-12)

- 'I shall go at once, but it may be too late'.

- 'I'd do it again, if I could'.

- 'Oh, Jo! Mrs. Hummel's baby is dead'.

2) Ex.14, Find answers to these questions. (Chapters
13-14)

- Why did Jo get so angry with Laurie?

- Why wouldn't Laurie tell his grandfather what he had done?

\section{8) Practicing language skills}

1) Ex. 1. Choose a character and read her parts of the dialogue aloud. If the characters are not enough for all students, take turns.

2) Ask your teacher to help you if you do not know how to pronounce difficult phrases.

\section{9) Homework}

3) Ex. 2. Jo and Laurie will meet again in three years, after Laurie has been to college. Write about 150 words saying what you think will happen to them

10) Student personal growth

4) Ex. 1. When Mr. March comes home, he thinks that his daughters have changed. In what ways do you think they are different? Write a few sentences about each of the four, describing the changes.

\section{CONCLUSION}

Having devised a number of exercises based on a simplified version of Alcott's novel we come up with the conclusion that the greater number of learners will take advantage from the use of the suitable literary texts in the classroom. Finally, we should say that teachers can create similar activities but always according to the needs of the group they teach.

\section{REFERENCES}

[1] G. Lazar, Literature and Language Teaching, Cambridge University Press, 1993.

[2] I. Murdoch, "Existentialist Hero," The Listener, vol. 23, pp. 52, March 1950 .

[3] E. Pound, How to Read, Haskell House, 1971.

[4] R. P. Boas, The Study and Interpretation of Literature, Harcourt: Brace and Company Inc., 1931.

[5] B. Christopher and C. Ronald, Literature and Language Teaching, Oxford University Press, 1997.

[6] A. Duff et al., Literature, Oxford: Oxford University Press, 1990.

[7] M. Sanz and C. Fernandez, Principios Metodologicos de los Enfoques Comunicativos, Madrid: Fundacion Antonio Nebrija, 1997.

[8] P. A. Llach, "Teaching Language through Literature: the Waste Land in the ESL classroom," Odisea, no. 8, 2007.

[9] H. G. Widdowson, "H. G. Widdowson on literature and ELT," Talking Shop, ELT Journal 37, vol. 1, pp. 30-35, 1983.

[10] A. R. Carter and N. M. Long, Teaching Literature, Longman Publications, 1991.

[11] J. Collie and S. Slater, Literature in Language Classroom, Cambridge: Cambridge University Press, 1987.

[12] Braz da S. Ronivaldo, "Using Literary Texts in the ESL Classroom," vol. 1, no. 2, pp. 171-178, July 2001.

[13] M. Hismanoglou, "Teaching English through Literature," Journal of Language and Linguistics, vol. 1, no. 1, April 2005.

[14] H. Sage, Incorporating Literature in ESL Instruction, New Jersey: Prentice-Hall Inc., 1987.

[15] S. Arıogul, "The Teaching of Reading Through Short Stories in Advanced Classes" M.A. Thesis, Ankara: Hacettepe University, 2001.

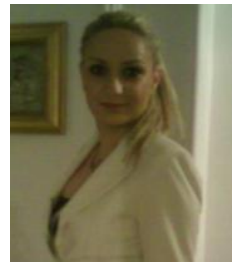

Koutsompou Violetta-Irene was born and raised in Polidrosos, a village at the outskirts of Mountain Parnassos, in Greece. She holds a BA in English and psychology (2007) from the State University of New York, USA, a masters degree in English and comparative literature (2009) from the University of Indianapolis, USA, an accredited Certificate in TEFL from the Hellenic American Union (2007) and a 
Diploma in Counseling Psychology (2013) from City Unity College, Athens, Greece, She is completing an MSc in Psychology with the University of East London, UK (2013-14) and she is working towards her thesis concerning postnatal depression on an MA in Counseling Psychology with the City University of Seattle, USA. Her areas of interest and concentration are psychology of child development, children's literature and its impact on the cognitive development, depression, grief and loss, stress management, second language acquisition, the use of literature in the language classroom and its benefits, postmodern literature, women's psychology and writings, book editing and writing. She has conducted research concerning second language acquisition and the young learners as well as grief, counseling and the grieving process in all aspects of life; she has participated as a co-author in a forthcoming book on grief and loss. She has presented her work in many Conferences in Greece and abroad. Ms Koutsompou worked in private language institutions since 2005; she was interested and worked with children with special learning difficulties such as dyslexia, as well as with children with behavioral problems in the language classroom.

She has published several papers, including: Koutsompou Violetta-Irene, "Young Learners: How advantageous is the early start?" IOSR Journal Of Humanities And Social Science (IOSR-JHSS) Vol. 15, Issue 5 (Sep. - Oct. 2013), pp 27-37 Kotsopoulou Anastasia and Koutsompou Violetta-Irene, "The Grieving Process during the Economic Crisis in Greece", Journal of Economics, Business and Management vol. 2, no. 4, pp.313-317, 2014. 